\title{
AVALIAÇÃO DO BEM ESTAR DE ANIMAIS DE COMPANHIA NA COMUNIDADE DA VILA FLORESTAL EM LAGOA SECA/PB
}

\section{(Evaluation of welfare companion animal in the Vila Florestal community in Lagoa Seca/PB)}

\author{
Camila Firmino de Azevedo, Benedito Marinho da Costa Neto, Ana Carolina Bezerra, \\ Alfredo Rosas de Lima Júnior \\ *Correspondência: camfiraze@bol.com.br
}

RESUMO: Com o intuito de fornecer subsídios que norteiem futuras ações de educação socioambiental para a melhoria do bem estar animal, foi realizado um trabalho investigativo com o objetivo de avaliar o bem estar de animais de companhia na comunidade da Vila Florestal em Lagoa Seca/PB. Para tal, foram realizadas entrevistas semiestruturadas através da aplicação de questionários durante visitas domiciliares a fim de traçar o perfil das famílias residentes na comunidade em relação à saúde pública e ao bem estar de cães e gatos. $O$ procedimento amostral visou obter um número de famílias entrevistadas que fosse representativo da população e os dados coletados foram analisados a partir de análise estatística descritiva. Foi observado que $68 \%$ das famílias visitadas na Vila Florestal em Lagoa Seca/PB possuem cães e/ou gatos, porém a minoria destes tem o hábito de higienizar, vacinar e vermifugar seus animais. De forma geral, os moradores desta comunidade desconhecem aspectos importantes relativos à guarda responsável e de manejo dos animais de companhia, sendo que o poder aquisitivo mostra a impossibilidade da procura por serviços veterinários, como atendimento médico veterinário e vacinações. A pesquisa também fornece dados importantes que podem servir de subsídio para futuras ações pelo bem estar e saúde animal e, além disso, torna evidente a necessidade de ações educativas sobre guarda responsável, prevenção de doenças e também a necessidade de um serviço público veterinário para toda a população, contribuindo assim para a saúde pública local.

Palavras-chave: cães; educação socioambiental; gatos; guarda responsável; saúde pública

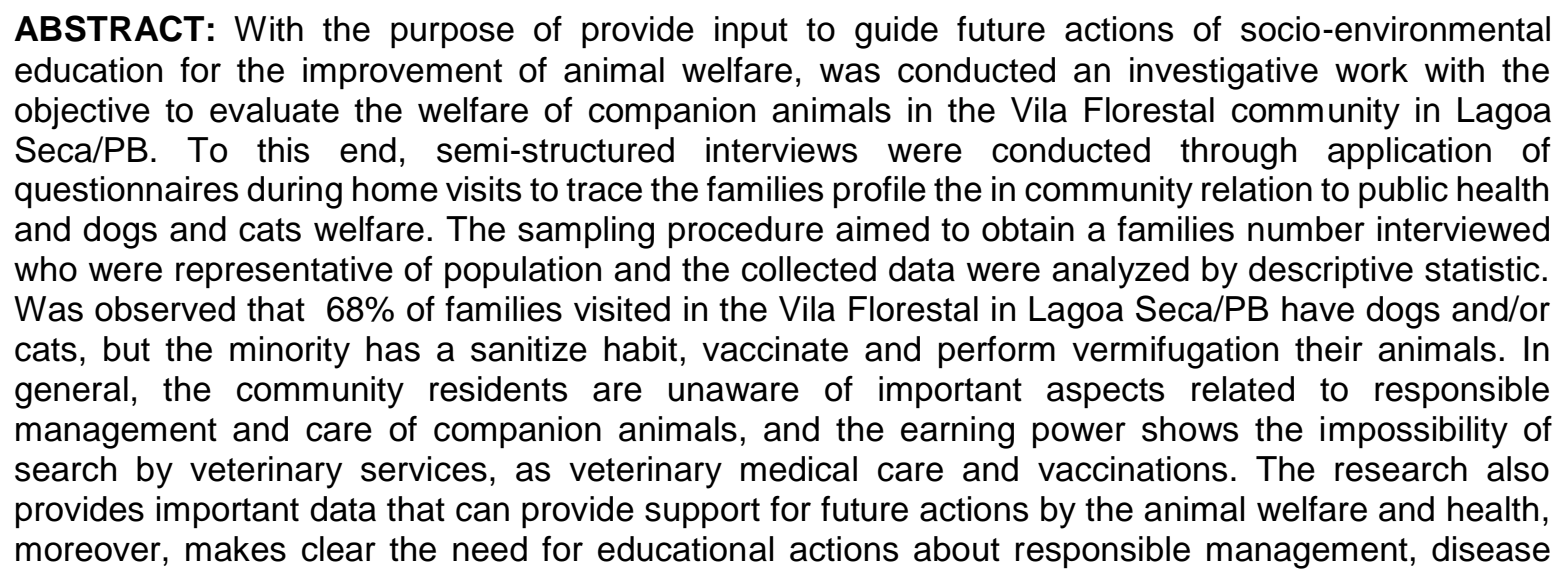

Recebido em 10/03/2014

Aprovado em 21/08/2015 
prevention and but also the need of a veterinary public service for all population, contributing to the local public health.

Key Words: cats; dogs; public health; responsible management; socio-environmental education. 


\section{INTRODUÇÃO}

Nas últimas

décadas, principalmente nas sociedades consideradas mais desenvolvidas, temse vindo a utilizar os animais, de forma sistematizada, em contextos terapêuticos e como auxiliares para minorar alguns efeitos de diversos tipos de deficiência. Este fato ocorre, especialmente, porque os animais são dotados de senciência, que segundo Singer (2004) é a "capacidade de sofrer, sentir prazer ou felicidade"; sendo que todos os animais vertebrados são senscientes, isso implica dizer que são capazes de sentir e estar de si próprio ou do ambiente que lhe cerca.

Beck e Katcher (1996) ressaltam que os animais possuem um conjunto de qualidades particulares, de onde se destaca 'o amor incondicional e espontâneo que manifestam em relação ao ser humano'. E segundo Garcia et al. (2008), o animal tem a 'capacidade de fazer o ser humano sentir-se amado, respeitado, aceito, seguro e digno de atenção'.

Porém, a grande parte da população não oferece os cuidados e tratamentos adequados aos seus animais, seja por negligência, falta de informação ou até mesmo crueldade. Deste fato, resultam inúmeros problemas que afetam tanto seres humanos como animais, tais como abandono dos mesmos nas ruas (SOTO et al., 2007), causando aumento do número de acidentes de trânsito e zoonoses (SCHOENDORFER, 2001); redução da qualidade e expectativa de vida dos animais; além das crias indesejadas, que aumentam ainda mais a superpopulação e o abandono (BORTOLOTI e D'AGOSTINHO, 2007); tornando de extrema relevância os programas de educação sanitária e ambiental com a finalidade de reduzir esses problemas. Limbert et al. (2009) ressaltam ainda que a deficiência dos programas públicos de educação sanitária e ambiental dificulta a percepção e entendimento, especialmente em comunidades carentes, dos riscos à saúde a que estas pessoas e animais estão expostos. Com o intuito de minimizar estes problemas, Magalhães et al. (2008) apontam a necessidade de desenvolver a compreensão de guarda responsável de animais de estimação como um prérequisito para assegurar que os animais de companhia recebam os cuidados indispensáveis ao seu bem-estar e daqueles com quem convivem; e que ainda a não assimilação deste conceito contribui para o aumento da população de cães e gatos.

Por estes motivos, reconhece-se a importância dos programas de educação socioambiental relacionados ao bem estar homem-animal. Segundo Molento (2007), cabe à atuação em bem-estar um estudo da interação entre seres humanos e animais de companhia de forma a localizar pontos críticos para a qualidade de vida, seguido de propostas de melhoria. Neste último plano, esperase que os avanços nesta área permitam a pesquisa e a atuação em componentes em torno dos quais, historicamente, se formaram lacunas técnicas, em especial em relação ao descontrole populacional de animais de companhia em centros urbanos.

Dessa forma, conhecer o perfil de proprietários de animais pode ser de grande valia para os profissionais da área, incluindo médicos veterinários, especialistas em saúde pública, entre outros, a fim de que se possam adotar estratégias para divulgar a guarda responsável e o bem estar animal, minimizando o abandono e os maus tratos (SILVA et al., 2009) e consequentemente promovendo melhorias na saúde pública.

Diante do exposto, objetivou-se avaliar o bem estar de animais de companhia na comunidade da Vila Florestal em Lagoa Seca/PB, com o 
intuito de fornecer subsídios para futuras ações educativas que envolvam os temas guarda responsável e bem estar animal.

\section{MATERIAL E MÉTODOS}

Para a realização das atividades referentes à pesquisa, foi realizado um trabalho investigativo através de entrevistas semiestruturadas na comunidade da Vila Florestal de Lagoa Seca/PB, com o intuito de traçar um perfil da população em relação ao tema bem estar animal e guarda responsável de animais de companhia, a fim de permitir o estabelecimento de ações educativas e de conscientização. Foram aplicados questionários sócio-comportamentais e epidemiológicos durante visitas domiciliares, que abordaram questões relevantes para o conhecimento da forma que os entrevistados tratam e se relacionam com os animais.

A Vila Florestal está localizada zona rural do município de Lagoa Seca/PB, onde vivem aproximadamente 400 famílias consideradas de baixa renda e em situação de vulnerabilidade social, observando-se grande quantidade de animais errantes e semidomiciliados.

A equipe não se limitou em simplesmente aplicar os questionários, pois durante as entrevistas, trabalhou com informações básicas em educação socioambiental para o bem estar animal, na medida em que procurou esclarecer as dúvidas da população em relação à guarda responsável. Também foram abordadas questões relativas a hábitos de higiene, respeito aos animais e preservação da dignidade, saúde e vida dos mesmos.

É sabido que o processo de educação em saúde, assim como a avaliação dos dados obtidos devem ser contínuos (SOTO et al., 2006); por este motivo, foi realizado um diagnóstico de situação, com caráter informativo, visando direcionar os órgãos competentes para medidas futuras de educação continuada ambiental e em saúde.

O procedimento amostral visou obter um número de famílias entrevistadas que fosse representativo da população residente na Vila Florestal de Lago Seca/PB e os dados coletados durante a aplicação dos questionários foram analisados a partir de análise estatística descritiva mediante determinação dos percentuais observados nas categorias das variáveis.

\section{RESULTADOS E DISCUSSÃO}

As 100 entrevistas foram realizadas durante visitas domiciliares na comunidade da Vila Florestal em Lagoa Seca/PB. $\mathrm{Na}$ oportunidade foram entrevistados 21 homens e 79 mulheres, sendo que destes $50 \%$ são solteiros, $45 \%$ são casados e $5 \%$ são viúvos. No que se refere à escolaridade dos entrevistados, $8 \%$ são analfabetos, 9\% escrevem apenas o nome, 39\% cursaram o Ensino Fundamental I, 24\% cursaram o Ensino Fundamental II, 19\%, o ensino médio e apenas $1 \%$ dos entrevistados cursaram o ensino superior. A renda mensal da maioria dos entrevistados não passa de um salário mínimo (89\%) e levando em consideração o índice de potencial de consumo 2013, a maiorias dos entrevistados então dentro das classes $D$ e E.

A relação da escolaridade e renda familiar com a guarda de animais de companhia também já foi avaliada em outras pesquisas. Langoni et al. (2011) observou que os níveis de escolaridade predominantes entre os entrevistados em Botucatu/SP foram fundamental e médio, totalizando 78,6\%. Martins (2009) verificou que da população que tinha animais domésticos na cidade de Pinhais/PR, 46,46\% apresentava renda familiar de até dois salários mínimos, e 
$32,02 \%$ de dois a quatro salários mínimos.

Das 100 casas visitadas, 68 possuíam animais e 32 casas, não. Sendo que dos 68 entrevistados que possuem animais, $37(54,41 \%)$ possuem cães, $7(10,29 \%)$ possuem gatos, 21 $(30,88 \%)$ possuem as duas espécies (cão e gato) e $3(4,41 \%)$ possuem outros animais (Figura 1); perfazendo um total de 170 animais (81 fêmeas e 89 machos na comunidade, entre cães e gatos). É importante mencionar que este número se refere aos animais da comunidade que apresentam proprietários e não reflete o número total de animais, já que além destes existem aqueles que são errantes e sua guarda não é considerada por nenhuma pessoa ou família da Vila Florestal - Lagoa Seca/PB.

A predominância de cães nas famílias da comunidade avaliada em relação ao número de gatos também já foi observada por meio de várias outras pesquisas realizadas em outras cidades brasileiras, a exemplo de Botucatu/SP (LANGONI, 2011), Garça/SP (PINHEIRO JÚNIOR, 2006), Dourados/MS (LIMBERT et al., 2009), Ibiúna/SP (SOTO et al., 2006) e Teresina/PI (SILVA et al., 2009).

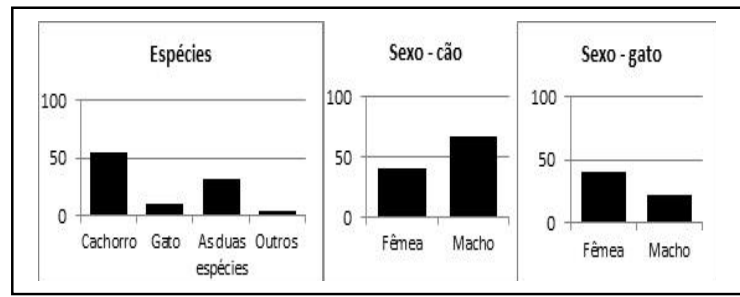

Figura 1 - Animais de companhia presentes na comunidade da Vila Florestal em Lagoa Seca/PB. A. Espécies. B. Sexo dos cães. C. Sexo dos gatos.

Em relação à forma de aquisição dos animais (Figura 2), dos 68\% dos entrevistados que afirmaram possuir animais, $54,41 \%$ declararam que ganharam de algum parente ou vizinho; $19,11 \%$, que adotaram da rua, $10,29 \%$, que adotaram de pessoas ou de ONGs; $2,94 \%$, que compraram o animal; e $13,23 \%$ responderam mais de uma opção. Na grande maioria das vezes, no momento em que foram adquiridos, estes eram filhotes $(60,29 \%)$ ou adultos $(20,58 \%)$. Dentre os motivos que levaram as pessoas a adquirirem os animais de companhia, gostar de animais $(48,52 \%)$, segurança $(10,29 \%)$ e para as crianças da família brincarem $(1,47 \%)$ estão entre os mais mencionados.

De acordo estudo realizado com 242 famílias em Garça/SP por Pinheiro Júnior et al. (2006), dentre os gatos observados, $36 \%$ foram obtidos para companhia e $64 \%$ para outra finalidade; segundo informações destes proprietários, $96 \%$ dos gatos recebem atenção de seus proprietários e apenas $4 \%$, não. Já com relação aos cães, a maioria foi obtida para companhia $(63,89 \%)$, para guarda $(21,67 \%)$ e para outros motivos $(14,44 \%)$.

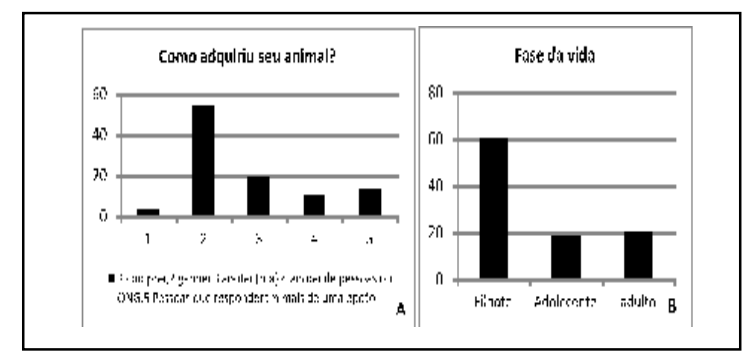

Figura 2 - Forma de aquisição dos animais de companhia na comunidade da Vila Florestal em Lagoa Seca/PB. A. Como adquiriu seu animal? B. Fase da vida no momento da aquisição.

Quando questionados a respeito dos cuidados tomados com seus animais sobre a alimentação (Figura 3A), 41,17\% falou que alimenta seu animal com comida caseira; $22,05 \%$, apenas com ração; e $36,76 \%$, com ração e comida caseira. E em relação ao banho dos animais (Figura 3B), 39,70\% respondeu que dá banho semanalmente, $27,94 \%$ quinzenalmente, $7,35 \%$ mensalmente e $10,29 \%$ raramente. Os dados observados relativos à alimentação não 
diferiram significativamente de estudo feito por Langoni et al. (2011) em Botucatu/SP, no qual identificou que dentre os entrevistados, $28,3 \%$ relataram fornecer tanto comida caseira quanto ração; já 41,4\% afirmaram alimentar seus animais com um tipo de alimento, sendo que $17 \%$ destes forneciam comida caseira e $83 \%$, apenas ração. Em relação à higiene, os mesmos autores observaram que $43,3 \%$ das pessoas entrevistadas recorrem à prática de banhos semanais e 28,3\%, com frequência mensal; os demais não higienizam seus animais. Esses dados diferem do que foi observado nesta pesquisa, em que de forma geral, grande parte dos proprietários não tem o hábito de dar banho nos seus animais.

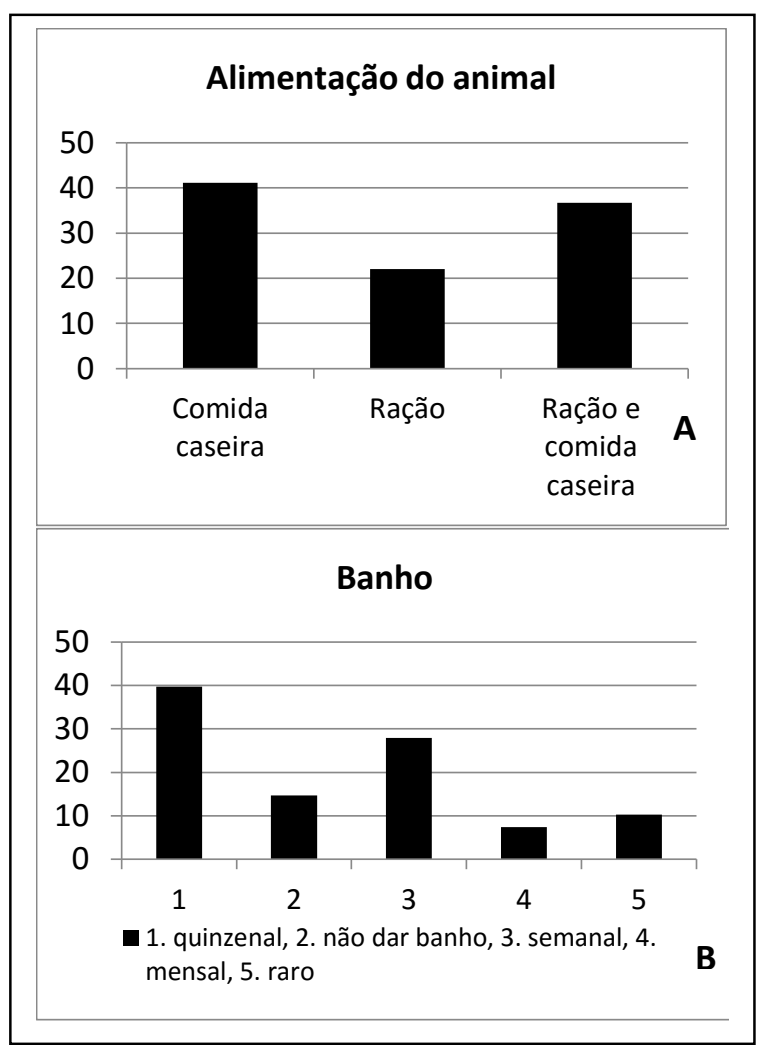

Figura 3 - Cuidados com os animais de companhia na comunidade da Vila Florestal em Lagoa Seca/PB. A. Alimentação do animal B. Banho e higienização.

É importante considerar que uma alimentação saudável e hábitos de higiene são extremamente importantes para manter a saúde do animal, reduzindo assim o risco de transmissão das doenças conhecidas como zoonoses, tanto para outros animais como para os seres humanos (SAÚDE, 2003; BROOM e MOLENTO, 2004; SANTANA e OLIVEIRA, 2006).

Levando-se em consideração os $68 \%$ dos entrevistados, percebe-se que pouco mais de $17 \%$ já levou seu animal ao veterinário, $11,76 \%$ já levou em algum momento e $70,58 \%$ nunca visitaram o veterinário com seu animal (Figura $4 \mathrm{~A}$ ). Quando questionados sobre o motivo da visita ao veterinário (Figura 4B), os entrevistados deram as seguintes respostas: doença, envenenamento, tosse, infecção urinária e virose. Em estudo realizado em Teresina/PI, foi observado que a maioria $(75,3 \%)$ das pessoas também nunca levou o cão ao médico veterinário (Silva et al., 2009).

Visitas periódicas ao veterinário são de grande importância para saúde do animal, uma vez que este pode transmitir algumas doenças. Guarda responsável de animais de companhia se configura como uma das práticas para promoção do bem estar animal, sendo de fundamental importância e diretamente relacionada ao papel do médico veterinário na sociedade, que fornece subsídios para conscientização quanto às necessidades básicas para uma relação saudável tanto para os animais, quanto para seus proprietários, independente do senso comum, muitas vezes equivocado (SILVANO, 2010).

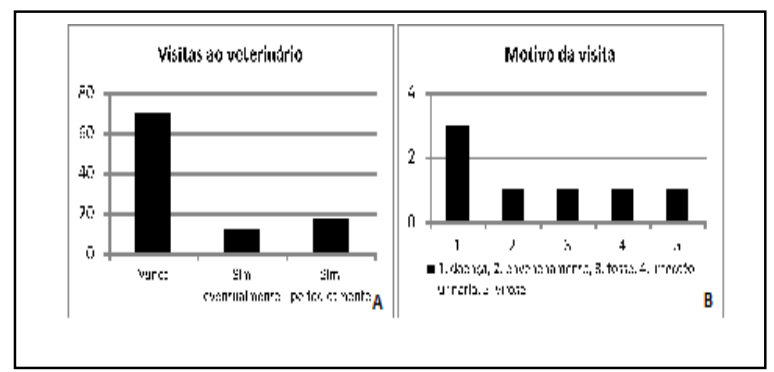

Figura 4 - Dados relativos a visitas ao veterinário dos animais de companhia presentes na comunidade da Vila Florestal em Lagoa Seca/PB. A. Visitas ou veterinário $B$. Motivo da visita.

Quando questionados se em algum momento os animais já teria sido 
vermifugados (Figura 5A), 44,12\% responderam que sim e 55,88\% responderam que não. Posteriormente foi perguntado quem indicou 0 vermífugo, dos entrevistados que responderam $\operatorname{sim}(44,12 \%), \quad 26,66 \%$ relataram que foi indicado pelo agente de saúde, $20 \%$ amigo ou algum familiar, $13,33 \%$ vendedor e $40 \%$ pelo veterinário.

Ao serem perguntados sobre a vacinação (Figura $5 \mathrm{~B}$ ), os que são tutores $(68 \%)$ responderam que já vacinaram seu animal; sendo que $54,47 \%$ vacinam anualmente contra raiva durante as campanhas do governo. $16,17 \%$ vacinaram apenas uma ou duas vezes, $1,47 \%$ vacinam contra a raiva no veterinário, $1,47 \%$ vacinam com a antiviral e $29,41 \%$, disseram que nunca vacinaram seu animal.

No âmbito da vacinação, especialmente a antirrábica, esta tem de ser ampla e acessível para a população, com a promoção, pelo Estado, de amplas e intensas campanhas educacionais na mídia e nas escolas, tratando da necessidade de se vacinar o animal, aproveitando-se da ocasião para efetivar a educação para a guarda responsável, visando erradicar as zoonoses e elevar o bem estar animal e humano; além de tornar-se obrigatória e gratuita a vacina contra a raiva (SILVANO et al., 2010).

No Brasil, devido à situação imunológica da raiva, cujo principal reservatório do ciclo urbano é o cão, foi instituído em 1973 o Programa Nacional de Profilaxia da Raiva (PNRP) (BARROSO e LIMA, 2012). Em 1977, mediante convênio firmado entre os Ministérios da Saúde e Agricultura, a extinta Central de Medicamentos (CEME) e a Organização Pan-americana de Saúde, iniciaram-se medidas sistemáticas de vacinação antirrábica canina, implantando-se a vigilância epidemiológica da doença (SANTOS, 2006).

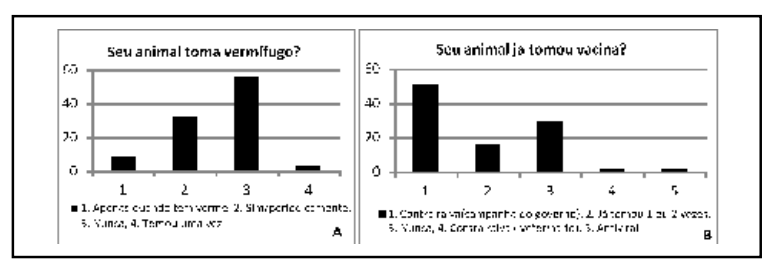

Figura 5 - Dados em relação à vermifugação e vacinação dos animais de companhia presentes na comunidade da Vila Florestal em Lagoa Seca/PB. A. Seu animal toma vermífugo? B. Seu animal já tomou vacina?

Dos $68 \%$ dos entrevistados, quando questionados se em algum momento seus animais tinham dado cria (Figura $6 \mathrm{~A}$ ), 29,41\% respondeu que sim e $70,58 \%$ respondeu que não. $E$ no intuito de avaliar qual destino das crias destes animais, os mesmos foram indagados sobre o que fizeram com os filhotes (Figura 6B), destes 4 entrevistados responderam que deixaram na própria casa, 3 responderam que os filhotes tinham morrido, 6 afirmaram que tinham encaminhado os filhotes para adoção e 1 entrevistado respondeu que tinha abandonado os filhotes no lixão. Essas crias poderiam ser evitadas através da esterilização cirúrgica e dessa forma ser reduzido a superpopulação e 0 consequente abandono dos animais (BORTOLOTI e D'AGOSTINHO, 2007), como preconizado pela Organização Mundial de Saúde (OMS) (SAÚDE, 2003). A OMS considera ineficientes as atividades isoladas de recolhimento e eliminação de cães e gatos como finalidade de controle populacional e, além disso, preconiza as ações para conter a falta de responsabilidade do ser humano quanto à guarda dos animais (WHO, 1990). 


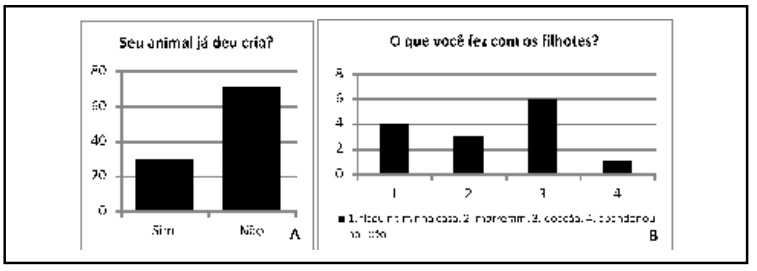

Figura 6. Dados em relacionado à crias de animais de companhia presentes na comunidade da Vila Florestal em Lagoa Seca/PB. A. Seu animal já deu cria? B. O que você fez com os filhotes?

Entre todos os entrevistados, $92 \%$ respondeu que nunca tinham abandonado um animal e $8 \%$ afirmaram que em algum momento já tinha abandonado (Figura 7A). Quanto aos motivos pelos quais os entrevistados não abandonariam (Figura 7B), 6\% dos entrevistados responderam por que gosta de animais, 3\% que não tem coragem, $1 \%$ respondeu que os animais são a alegria da casa, $1 \%$ respondeu que não abandonaria para o animal não passar fome nas ruas e $1 \%$ porque é uma vida.

Quando perguntados se existia muito animais abandonados em sua rua, $74 \%$ responderam que sim e $26 \%$ responderam que não. Levando-se em consideração os $74 \%$ que responderam sim, quando foram questionados se esses animais abandonados já tiveram donos, 87,83 responderam que sim e $12,16 \%$ responderam que não. $E$ com relação a alguém ajudar esses animais, $74,32 \%$ dos entrevistados responderem que alguém da rua ajuda e 25,67 responderam que não.

Segundo o Art. 32. da Lei Federal de Crimes Ambientais, abandonar, praticar ato de abuso, maus-tratos, ferir ou mutilar animais silvestres, domésticos ou domesticados, nativos ou exóticos é crime, passível de pena (detenção de três meses a um ano e multa). Como consequência do abandono, a densidade populacional de animais errantes, vulgarmente denominados "vira-latas", alcança números incalculáveis nas ruas das grandes cidades. Um dos principais problemas oriundos da superpopulação desses animais decorre de os mesmos estarem expostos a todo tipo de doenças, intempéries e perigos, sendo vítimas de várias zoonoses, doenças carenciais e mutilações, constituindo um sério problema de saúde pública. Essa problemática é agravada em virtude do acelerado grau de reprodução e proliferação desses animais (SANTANA et al., 2004).

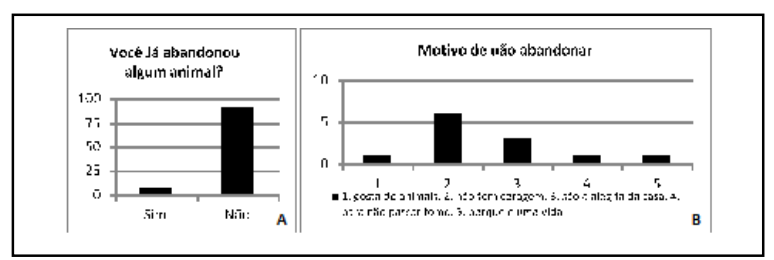

Figura 7. Dados em relacionado ao abandono de animais de companhia presentes na comunidade da Vila Florestal em Lagoa Seca/PB. A. Você já abandonou algum animal? B. Motivos de não abandonar.

\section{CONCLUSÃO}

De forma geral, os moradores da comunidade da Vila Florestal em Lagoa Seca/PB desconhecem aspectos importantes relativos à guarda responsável e de manejo dos animais de companhia. O poder aquisitivo mostra a impossibilidade da procura por serviços veterinários, como atendimento médico e vacinações. A pesquisa também fornece dados importantes que podem servir de subsídio para futuras ações pelo bem estar e saúde animal e, além disso, torna evidente a necessidade de ações educativas sobre guarda responsável, prevenção de doenças e também a necessidade de um serviço público veterinário para toda a população, contribuindo assim para a saúde pública local. 


\section{REFERÊNCIAS}

BARROSO, J.E.M.; LIMA, E.E. O centro de controle de zoonoses e sua importância para saúde pública do município de Catalão, GO. In: Conferência Internacional de Estratégia em Gestão, Educação e Sistemas de Informação, I, 2012, Goiânia. Anais... Goiânia: Universidade Estadual de Goiás, 2012, p. 846-859.

BECK, A.; KATCHER, A. Between Pets And People: The Importance of Animal Companionship. West Lafayette: Purdue University Press, 1996. 344 p.

BORTOLOTI, R., D'AGOSTINO, R.G. [2007]. Ações pelo controle reprodutivo e posse responsável de animais domésticos interpretadas à luz do conceito de metacontingência. Revista Brasileira de Análise do Comportamento. v.3, n.1, p.17-28, 2007. Disponível em: http://www.periodicos.ufpa.br/index.php/rebac/ar ticle/ viewArticle/821/ Acesso em: 25/02/2014.

BROOM, D.M.; MOLENTO, C.F.M. [2004]. Bemestar animal: conceito e questões relacionadas revisão. Archives of Veterinary Science, v.9, n.2, p.1-11, 2004. Disponível em: http://www.unb.br/posgraduacao/docs/fav/BEME STARANIMAL

CONCEITOQUESTOESRELACIONADAS.pdf/ Acesso em: 05/03/2014.

GARCIA, R.C.M.; MALDONADO, M.A.C.; LOMBARDI, A. [2008]. Controle populacional de cães e gatos. Ciência Veterinária Tropical, v.11, p.106-110, 2008.

LANGONI, H.; TRONCARELLI, M.Z.; RODRIGUES, E.C. et al. [2011]. Conhecimento da população de Botucatu-SP sobre guarda responsável de cães e gatos. Veterinária e Zootecnia. v.18, n.2, p.297-305, 2011. Disponível em: http://www.fmvz.unesp.br/rvz/index.php/rvz/articl e/view/97/ Acesso em: 05/03/2014.

LIMBERT, B.N.P. [2009]. Estudo da tríade: educação sanitária, posse responsável e bemestar animal em animais de companhia em comunidade de baixa renda. Anuário da Produção de Iniciação Científica Discente da Anhanguera, v.12, n.13, p.99-108, 2009. Disponível em: http://www.sare.anhanguera.com/index.php/ anuic/article/viewFile/1508/697/ Acesso em: 05/03/2014.

MAGALHÃES, F.J.R.; COSTA, D.G.C.; SILVS, J.C.R. et al. Ações para promover o controle populacional e sanitário de cães e gatos em Fernando de Noronha, PE. In: Congresso Brasileiro de Bioética e Bem Estar Animal, I,
2008, Recife. Anais...Recife: Conselho Federal de Medicina Veterinária, 2008, p. 3.

MARTINS, C.M. Relação entre a posse de cães e gatos com padrão socioeconômico e com a presença de crianças nas residências no município de Pinhais-PR. In: Evento de Iniciação Científica da Universidade Federal do Paraná, 17ํㅡ. 2009. Curitiba. Anais...Curitiba: EVINCI, 2009.

MOLENTO, C.F.M. [2007]. Bem-estar animal: qual é a novidade? Acta Scientiae Veterinariae, v.35, n.2, p.224-226, 2007.

PINHEIRO Jr., O.A.; SILVA, M.O.C., ANGELA, H.L. et al. [2006]. Posse responsável de cães e gatos no município de Garça/SP. Revista Científica Eletrônica de Medicina Veterinária, v.3, n.6, p.1-4, 2006. Disponível em: http://faef.revista.inf.br/imagens_arquivos/arquiv os_destaque/3DHv9yBzqLrhlo2_2013-5-20-1526-52.pdf/ Acesso em: 02/03/2014.

SANTANA, H.J. [2004]. Abolicionismo Animal. Revista de Direito Ambiental. n.6, p.85-109, 2004.

SANTANA, L.R.; OLIVEIRA, T.P. [2006]. Guarda responsável e dignidade dos animais. Revista Brasileira de Direito dos Animais, v.1, n.1, p.207-230, 2006. Disponível em: http://www. abolicionismoanimal.org.br/artigos/gu ardaresponsvele dignidadedosanimais.pdf/ Acesso em: 07/03/2014.

SANTOS, A.G. Perfil Epidemiológico da População Canina Assistida pelo Serviço de Pronto Atendimento do Centro de Controle de Zoonoses Paulo Darcoso Filho. 2006. Rio de Janeiro, 74f. Dissertação (Mestrado em Ciências Veterinárias) - Curso de Pós-graduação em Ciências Veterinárias, Universidade Federal Rural do Rio de Janeiro.

SAÚDE, ORGANIZAÇÃO PAN-AMERICANA DA. Reunião Latino-americana de Especialistas em Posse Responsável de Animais de Companhia e Controle de Populações Caninas. Rio de Janeiro: WSPA, 2003.

SCHOENDORFER, L.M.P. Interação homemanimal de estimação na cidade de São Paulo: o manejo inadequado e as consequências em saúde pública. 2001. São Paulo, 82f. Dissertação (Mestrado em Saúde Pública) Faculdade de Saúde Pública, Universidade de São Paulo.

SILVA, F.A.N.; CARVALHO, R.L.; QUESSADA, A.M. [2009]. Posse responsável de cães no bairro Buenos Aires na cidade de Teresina (PI). Ars Veterinária, v. 25, n.1, p. 14-17, 2009. Disponível em: 
http://www.arsveterinaria.org.br/index.php/ars/art icle/ view/248/ Acesso em: 04/03/2014.

SILVANO, D.; BENDAS, A.J.R.; MIRANDA, M.G.N. et al. [2010]. Divulgação dos princípios da guarda responsável: uma vertente possível no trabalho de pesquisa a campo. Revista Eletrônica Novo Enfoque, v.9, n.9, p.64-86, $2010 . \quad$ Disponível em: http://www.castelobranco.br/sistema/novoenfoqu e/files/09/artigos/06.pdf/ Acesso em: 25/02/2014.

SINGER, P. Libertação animal. Porto Alegre, São Paulo: Lugano, 2004. 357 p.

SOTO, F.R.M.; RISSETO, M.R.; PINHEIRO, S.R. et al. [2006]. Avaliação de experiência com programa educativo de posse responsável de cães e gatos em escolas públicas do ensino fundamental da zona rural do Município de Ibiúnam, SP, Brasil. Revista Ciência em Extensão, v.2, n.2, p.10-20, 2006. Disponível em:

http://ojs.unesp.br/index.php/revista_proex/articl e/view/192/0/ Acesso em: 20/02/2014.

SOTO, F.R.M.; RISSETO, S.R.; BERNARDI, F. et al. [2007]. Motivos do abandono de cães domiciliados para eutanásia no serviço de controle de zoonoses do município de Ibiúna, SP, Brasil. Veterinária e Zootecnia, v.14, n.1, p.100106, 2007.

WHO, World Health Organization. Technical

Report Series, n. 913. Geneva: WHO, 2005. 